\title{
Comparative study of thin film n-i-p a-Si:H solar cells to investigate the effect of absorber layer thickness on the plasmonic enhancement using gold nanoparticles
}

\author{
Kazi Islam ${ }^{\text {a }}$, Farsad Imtiaz Chowdhury ${ }^{\mathrm{a}}$, Ali Kemal Okyay ${ }^{\mathrm{b}, \mathrm{c}, \mathrm{d}}$, Ammar Nayfeh ${ }^{\mathrm{a}, *}$ \\ ${ }^{\text {a }}$ Masdar Institute of Science and Technology, Institute Center for Microsystems - iMicro, Department of Electrical Engineering and Computer \\ Science (EECS), PO Box 54224, Abu Dhabi, United Arab Emirates \\ ${ }^{\mathrm{b}}$ UNAM-National Nanotechnology Research Center, Bilkent University, 06800 Ankara, Turkey \\ ${ }^{\mathrm{c}}$ Institute of Materials Science and Nanotechnology, Bilkent University, 06800 Ankara, Turkey \\ ${ }^{\mathrm{d}}$ Department of Electrical and Electronics Engineering, Bilkent University, 06800 Ankara, Turkey
}

Received 20 May 2015; received in revised form 9 July 2015; accepted 10 July 2015

Available online 5 August 2015

Communicated by: Associate Editor Nik Romeo

\begin{abstract}
In this paper, the effect of gold nanoparticles on n-i-p a-Si:H solar cells with different intrinsic layer (i-layer) thicknesses has been studied. $100 \mathrm{~nm}$ and $500 \mathrm{~nm}$ i-layer based n-i-p a-Si:H solar cells were fabricated and colloidal gold (Au) nanoparticles dispersed in water-based solution were spin-coated on the top surface of the solar cells. The Au nanoparticles are of spherical shape and have $100 \mathrm{~nm}$ diameter. Electrical and quantum efficiency measurements were carried out and the results show an increase in short-circuit current density $\left(J_{s c}\right)$, efficiency and external quantum efficiency (EQE) with the incorporation of the nanoparticles on both cells. $J_{s c}$ increases from $5.91 \mathrm{~mA} / \mathrm{cm}^{2}$ to $6.5 \mathrm{~mA} / \mathrm{cm}^{2}(\sim 10 \%$ relative increase) and efficiency increases from $3.38 \%$ to $3.97 \%$ ( $\sim 17.5 \%$ relative increase) for the $100 \mathrm{~nm}$ i-layer solar cell after plasmonic enhancement whereas $J_{s c}$ increases from $9.34 \mathrm{~mA} / \mathrm{cm}^{2}$ to $10.1 \mathrm{~mA} / \mathrm{cm}^{2}(\sim 7.5 \% \mathrm{relative}$ increase) and efficiency increases from $4.27 \%$ to $4.99 \%(\sim 16.9 \%$ relative increase) for the 500 nm i-layer cell. The results show that plasmonic enhancement is more effective in $100 \mathrm{~nm}$ than $500 \mathrm{~nm}$ i-layer thickness for a-Si:H solar cells. Moreover, the results are discussed in terms of light absorption and electron hole pair generation.
\end{abstract}

(C) 2015 Elsevier Ltd. All rights reserved.

Keywords: Photovoltaics; Solar cells; Thin-film; Nanoparticles; Plasmonic

\section{Introduction}

Thin film solar cells have gained a lot of interest as it offers the potential to bring down the cost of the solar cell due to the reduced material volume. But obtaining high efficiency in thin film solar cell still remains a challenge as a significant fraction of the solar spectrum passes through

\footnotetext{
* Corresponding author. Tel.: +971 2810 9105; fax: +97128109101.

E-mail address: anayfeh@masdar.ac.ae (A. Nayfeh).
}

the cell without being absorbed. Light trapping, which increases the optical path of the light inside absorber layer, is really important to increase the efficiency of thin film solar cells. For conventional thick film Si solar cell, light trapping is achieved by surface roughening but for thin film solar cell nanoscale texturing is required, due to its thinner absorber material, which is difficult to obtain and also tends to increase surface recombination and reduced material quality. Hence different approaches have been investigated like plasmonic (Atwater and Polman, 2010; 
Catchpole and Polman, 2008; Ferry et al., 2008), diffraction gratings (Haase and Stiebig, 2007; Heine and Morf, 1995; Michel and Kimerling, 2007), photonic crystals (Bermel et al., 2007; Campbell et al., 2000; Zhou and Biswas, 2008) to achieve high efficiency from thin film solar cells.

Plasmonic solar cell, where metal nanoparticles are used to scatter light in the absorber layer as shown in Fig. 1, are of great interest as they are easy to fabricate, do not interfere with cell processing and do not increase the cell surface area which might cause degradation in performance of solar cell. Metal nanoparticles embedded in a dielectric material can produce strong scattering at a particular wavelength due to localized surface plasmons. These are the collective oscillation of the free electrons at the metal boundary. Upon the excitation with incident light, movement of electrons leads to a polarization charge close to resonance frequency and incident light in the region of this resonance either gets absorbed or scattered (Maier and Atwater, 2005). The increase of photocurrent in solar cell by metal nanoparticles can be explained by this light scattering mechanism, which is one of the two prominent mechanisms that can explain the contribution of metal nanoparticles. The other mechanism is known as near-field localization effect (Temple et al., 2009). Assuming that metal nanoparticles are spherical and the size of the particles are well below the wavelength of the incoming light, the scattering and absorption cross sections in the dipole approximation (first order quasi-static approximation of the exact Mie solution) are given by Bohren and Huffman (1983):

$C_{\text {scat }}=\frac{1}{6 \pi}\left(\frac{2 \pi}{\lambda}\right)^{4}|\alpha|^{2}$

$C_{\mathrm{abs}}=\frac{2 \pi}{\lambda} \operatorname{Im}[\alpha]$

where

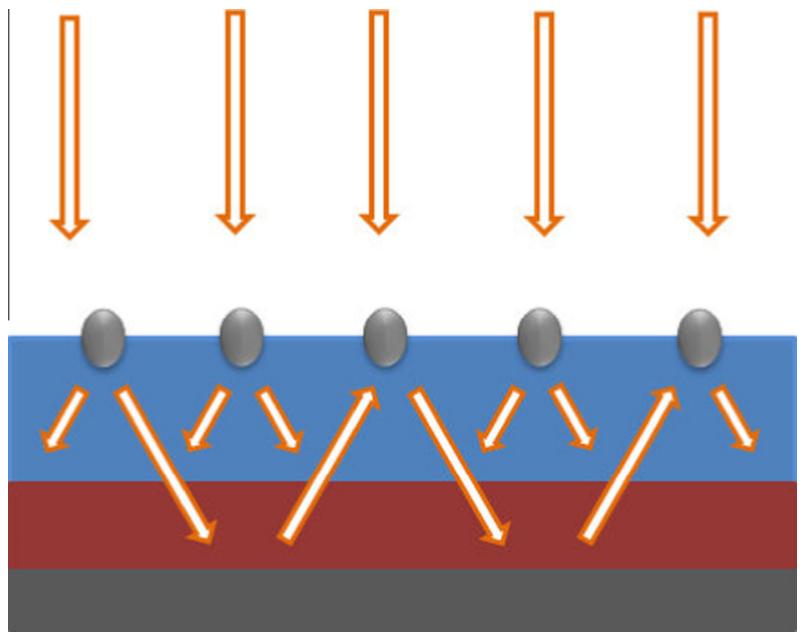

Fig. 1. Light trapping by forward scattering from metal nanoparticles placed on top of solar cell. $\alpha=3 V\left[\frac{\frac{\varepsilon_{p}}{\varepsilon_{m}}-1}{\frac{\varepsilon_{p}}{\varepsilon_{m}}+2}\right]$

is the polarizability of the particle. Here $V$ is the volume of the particle, $\varepsilon_{p}$ is the dielectric function of the particle and $\varepsilon_{m}$ is the dielectric function of the embedding medium. From Eq. (3), it is clear at $\varepsilon_{p}=-2 \varepsilon_{m}$, the particle polarizability will become very large and this concept is known as surface plasmon resonance. For light scattering it is important to have scattering cross section much larger than absorption cross section ( Bohren and Huffman, 1983; Derkacs et al., 2006).

Silver ( $\mathrm{Ag})$ and $\mathrm{Au}$ are the most commonly used metals for plasmonic application (Akimov and Koh, 2010; Naik et al., 2013; Sönnichsen et al., 2002). Ag is usually preferred because of its lower absorption losses and higher scattering cross section. But other factors such as surface termination, physical abundance and fabrication issues must also take into account. Ag is a rare metal, also it can form an absorbing oxide layer which causes damping and increase absorption (Akimov and Koh, 2010; Sönnichsen et al., 2002). On the other hand Au does not form any oxide layer (Temple and Bagnall, 2011). Moreover relatively large nanoparticle is desirable for a higher scattering cross section (Temple and Bagnall, 2012) and it has been shown that large $\mathrm{Au}$ nanoparticle will scatter more light in the forward direction than Ag nanoparticle (Paris et al., 2012) of similar size, making $\mathrm{Au}$ nanoparticle a good candidate to be used on the top side of the solar cell. Incorporation of these nanoparticles on top of solar cells can be done in various ways including drop-casting, dip coating etc. but spin coating remains desirable for large scale production due to its cost-effectiveness and ease of integration (Prevo and Velev, 2004; Shukla et al., 2004; Stuart and Hall, 1998; Xia et al., 2004). For this work, $100 \mathrm{~nm}$ Au nanoparticles were spin coated on top of two a-Si:H n-i-p solar cells with $100 \mathrm{~nm}$ and $500 \mathrm{~nm}$ i-layers and plasmonic enhancement was studied. It was found that plasmonic enhancement is more effective for a-Si:H solar cells that have $100 \mathrm{~nm}$ i-layer.

\section{Experiments}

Fig. 2 shows the structure of the fabricated thin film a-Si:H solar cells. The solar cell stack was grown on a $\mathrm{p}^{+}$ type $\mathrm{Si}$ wafer and consists of $20 \mathrm{~nm}$ heavily doped p-type $\mathrm{a}-\mathrm{Si}$, ' $x$ ' $\mathrm{nm}$ of undoped a-Si:H $(x$ being $100 \mathrm{~nm}$ and $500 \mathrm{~nm}$ ), $20 \mathrm{~nm}$ heavily doped n-type a-Si and finally $80 \mathrm{~nm}$ Indium Tin Oxide (ITO) on top (http://www. mvsystemsinc.com/researchand-development-services, 2014). The $\mathrm{p}^{+} \mathrm{Si}$ substrate served as the back contact, and did not contribute significantly to the carrier generation. At first, all the samples were cleaned using standard RCA cleaning procedure. The resultant chemical oxide preserves a high-quality c-Si surface which is important to minimize the amount of interface defects (Alnuaimi et al., 2013). 


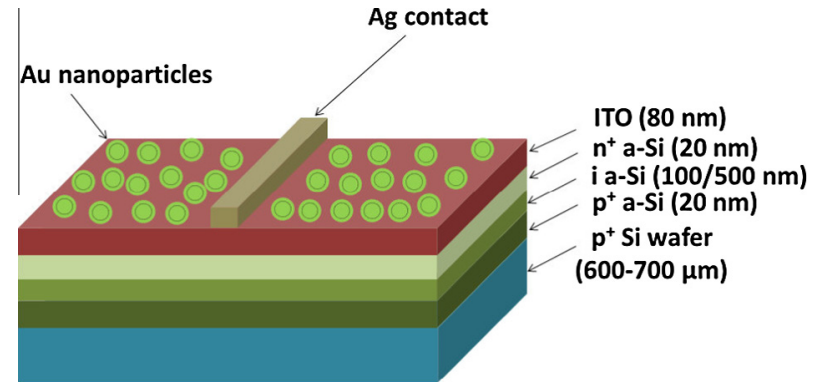

Fig. 2. Cross-section of the fabricated ITO/a-Si:H n-i-p solar cell with Au nanoparticles spin-coated on the top surface (figure not to scale).

Then the samples were flushed with diluted hydrofluoric acid (HF) to strip the covering oxide cap before loading into the vacuum deposition system. The $\mathrm{n}^{+}$, undoped and $\mathrm{p}^{+}$layers of a-Si:H were grown using Plasma Enhanced Chemical Vapor Deposition (PECVD) tool in a single run to minimize defects at the interfaces (Martins et al., 2000). Then $80 \mathrm{~nm}$ of ITO was sputtered on the top layer using RF sputtering tool (http://www.mvsystemsinc.com/ researchand-development-services, 2014). More details of the solar cell fabrication process can be found in (Abdul Hadi et al., 2014, 2011; Chowdhury et al., 2014; Islam et al., 2013). Afterwards $100 \mathrm{~nm} \mathrm{Au} \mathrm{nanoparticles} \mathrm{dis-}$ persed in Phosphate Buffered Saline (PBS) (http:// www.sigmaaldrich.com/materials-science/nanomaterials/ gold-nanoparticles, 2014) solution were spin-coated on top of ITO. The effect of Au nanoparticles size on the overall performance of the solar cell has been discussed elsewhere (Islam et al., 2014). After the nanoparticles coating, $100 \mathrm{~nm}$ of silver was deposited using E-beam Physical Vapor Deposition (PVD) tools and lift-off was performed to form the finger contacts. In order to determine the effect of these spin coated $\mathrm{Au}$ nanoparticles on different i-layer cells, External Quantum Efficiency (EQE) were measured and current-voltage $(J V)$ characterization were performed under 1-sun conditions. Three different cell area-sizes were fabricated i.e. $1 \mathrm{~cm} \times 1 \mathrm{~cm}, \quad 0.5 \mathrm{~cm} \times 0.5 \mathrm{~cm}$ and $0.25 \mathrm{~cm} \times 0.25 \mathrm{~cm}$. Unless otherwise stated, solar cells of size $0.25 \mathrm{~cm} \times 0.25 \mathrm{~cm}$ are presented in this work.

\section{Results and discussions}

The spin coating recipe was optimized to obtain uniform distribution as well as optimum concentration of particles on the surface. Several spin-coating recipes were investigated and SEM images were studied to see the distribution of nanoparticles. The most optimized spin-coating recipe was found to be $2000 \mathrm{rpm}$ speed, $1000 \mathrm{rpm}$ acceleration and spinning for $60 \mathrm{~s}$ which shows minimum non-conformal aggregation of nanoparticles. The surface coverage was also calculated using SEM images taken on different locations of the cells and was found to be $\sim 0.7854 \%$ with a variance of $\sim 0.016 \%$. ImageJ software were used for this calculation ("http://imagej.nih.gov/ij/,"
2015). For both the cells, same concentration and volume was used, and only 1 spin was carried out. More insight into the spin-coating optimization is described elsewhere (Islam et al., 2014; Israelowitz et al., 2014). Fig. 3 shows a SEM image of the top surface showing the Au nanoparticles on top of the solar cell.

Fig. 4 shows the $J-V$ curve for the reference cells and cells with $100 \mathrm{~nm}$ nanoparticles. The $J_{s c}$ tends to improve due to plasmonic enhancement for both $100 \mathrm{~nm}$ and $500 \mathrm{~nm}$ i-layer cells while $V_{o c}$ does not change significantly with nanoparticles or the i-layer thickness and remains at $0.89 \mathrm{~V}$. Table 1 summarizes the main findings of this work, listing the $V_{o c}, J_{s c}$, fill factor $(F F)$ and efficiency $(\eta)$ of the reference cells and cells with $100 \mathrm{~nm}$ nanoparticles. It also shows relative increase in $J_{s c}$ and efficiency of nanoparticles coated cells compared to reference cells for both $100 \mathrm{~nm}$ and $500 \mathrm{~nm}$ i-layer cells.

Fig. 5 shows EQE of the reference cells and nanoparticles coated cells. $1 \mathrm{~cm} \times 1 \mathrm{~cm}$ cells were used to perform EQE measurements. The results show an improved spectral response from the nanoparticles coated cells compared to reference cells. Peak EQE of the $100 \mathrm{~nm}$ i-layer cell is $51 \%$ for the cell with nanoparticles while the reference cell has $45 \%$ peak EQE. On the other hand, $500 \mathrm{~nm}$ i-layer reference cell has $61 \%$ peak EQE and nanoparticles enhanced cell has $65 \%$ peak EQE. These results show that nanoparticle incorporation has higher impact on $100 \mathrm{~nm}$ i-layer cell where relative improvement of the peak is around $13.33 \%$ than $500 \mathrm{~nm}$ i-layer cell where relative improvement of the peak is around $6.57 \%$.

All these results show that incorporation of $\mathrm{Au}$ nanoparticles increases the performance for both types of cells but $100 \mathrm{~nm}$ i-layer cell yields to larger relative performance enhancement by $\mathrm{Au}$ nanoparticles. This can be explained by analyzing the effect of metal nanoparticles on the incoming photos relative to the thickness of i-layer. Metal nanoparticles are capable of scattering the

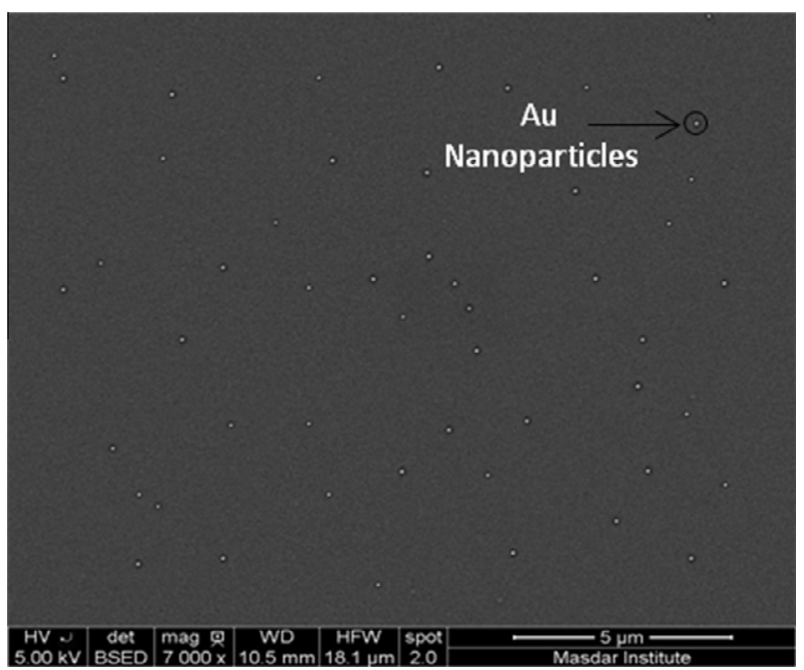

Fig. 3. SEM image of the top surface of the fabricated n-i-p a-Si:H solar cell with $100 \mathrm{~nm}$ Au nanoparticles on the ITO surface. 


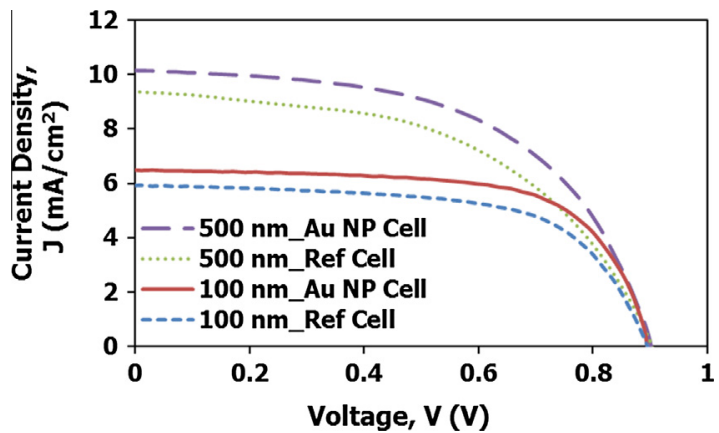

Fig. 4. Measured $J-V$ characteristics of n-i-p a-Si:H reference cells and cells with $100 \mathrm{~nm} \mathrm{Au}$ nanoparticles for both $100 \mathrm{~nm}$ and $500 \mathrm{~nm}$ i-layer cells.

incoming light. At the surface plasmon resonance, the scattering cross-section exceeds the geometrical cross section of the nanoparticles e.g. silver nanoparticles in air have a scattering cross-section that is approximately ten times the cross-sectional area of the particle at the resonant frequency (Soller and Hall, 2002). This scattering cross section depends heavily on the size of the nanoparticles. Smaller nanoparticles can only scatter a narrow range of wavelengths and also have higher absorption. Increasing the size of the nanoparticles broadens and attenuates the scattering peak and moves it to longer wavelength. Compared to smaller particles, larger particles have weaker peak scattering efficiency but can scatter a broader range of wavelengths and hence have a higher average scattering efficiency across the spectral range which will give a larger enhancement from the solar cell (Temple and Bagnall, 2012). More details on the trade-off between scattering and absorption by metal nanoparticles for plasmonic solar cell can be found elsewhere ( $\mathrm{Li}$ et al., 2014). Now, $100 \mathrm{~nm}$ Au nanoparticle can scatter a broader range of wavelength with a peak $\sim 560 \mathrm{~nm}$ which increases the optical path length inside the cell (http://nanocomposix.com/pages/ gold-nanoparticles-optical-properties, 2015). This optical path length refers to the distance that an unabsorbed photon may travel within the cell before it escapes out of the cell. Increasing the optical path length increases absorption inside the cell which is the reason for enhanced performance by both $100 \mathrm{~nm}$ and $500 \mathrm{~nm}$ i-layer cells after nanoparticle incorporation. For a cell with $100 \mathrm{~nm}$ absorber layer, any increase in optical path length can play a vital role in terms of absorption. Since the absorption is much higher in the first $100 \mathrm{~nm}$ than the next $100 \mathrm{~nm}$, any increase in the path length within the first $100 \mathrm{~nm}$

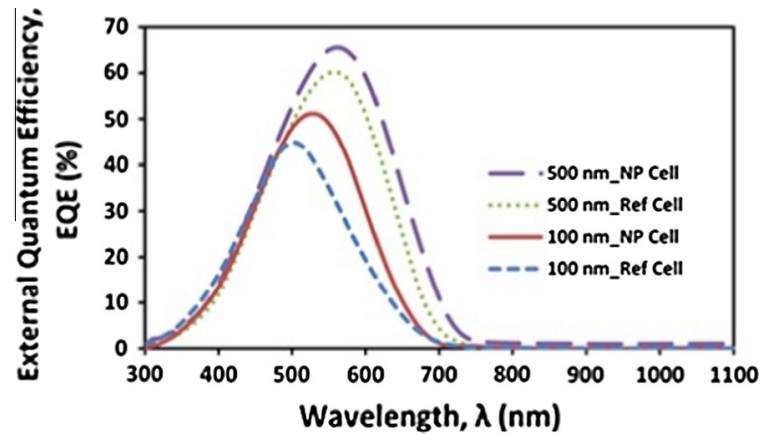

Fig. 5. Measured external quantum efficiency of n-i-p a-Si:H reference cells and cells with $100 \mathrm{~nm}$ Au nanoparticles for both $100 \mathrm{~nm}$ and $500 \mathrm{~nm}$ i-layer cells.

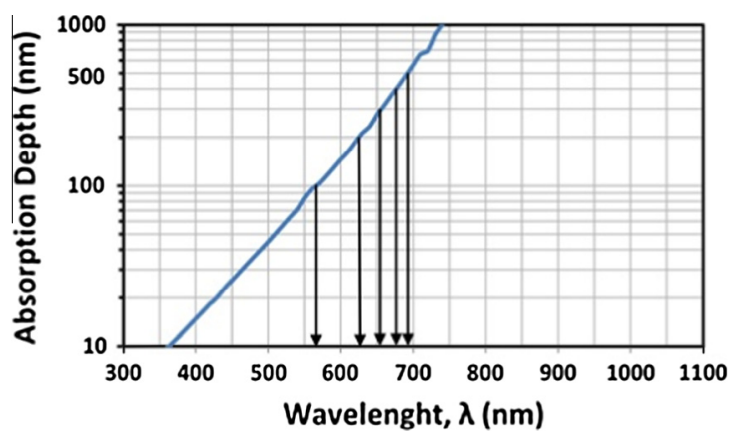

Fig. 6. Absorption depth profile of a-Si marking each $100 \mathrm{~nm}$ from 100 to $500 \mathrm{~nm}$.

absorber layer contributes more in photo-generation than any increase in the path length within $500 \mathrm{~nm}$ absorber layer. Fig. 6 shows the absorption depth (d) of a-Si material (http://www.pveducation.org/pvcdrom/pn-junction/ absorption-coefficient, 2015) which was calculated using the following equation:

$d=\frac{1}{\alpha}$

where $\alpha$ is absorption coefficient which has been determined at $300 \mathrm{~K}$ as a function of vacuum wavelength of light. It shows that the first $100 \mathrm{~nm}$ of the absorber from the top absorbs the spectrum up to $560 \mathrm{~nm}$. As the thickness increases, absorption by each $100 \mathrm{~nm}$ keeps on decreasing. An absorber layer of $500 \mathrm{~nm}$ can eventually absorb up to $690 \mathrm{~nm}$ of the spectrum. This is the reason for higher performance enhancement by $100 \mathrm{~nm}$ cell

Table 1

Summary of results.

\begin{tabular}{llllll}
\hline Cell & $V_{o c}(\mathrm{v})$ & $J_{s c}\left(\mathrm{~mA} / \mathrm{cm}^{2}\right)$ & $\Delta J_{s c}(\%)$ & $F F(\%)$ & $\eta(\%)$ \\
\hline $100 \mathrm{~nm}$ _Ref cell & 0.89 & 5.91 & 9.98 & 64 & 3.38 \\
$100 \mathrm{~nm} \_$Au NP cell & 0.89 & 6.5 & & 67 & 3.97 \\
$500 \mathrm{~nm}$ _Ref cell & 0.89 & 9.34 & 7.49 & 51 & 4.46 \\
$500 \mathrm{~nm}$ _Au NP cell & 0.89 & 10.04 & & 56 & 4.99 \\
\hline
\end{tabular}


compared to $500 \mathrm{~nm}$ cell with the incorporation of $\mathrm{Au}$ nanoparticles.

\section{Conclusion}

In summary, the effect of i-layer thickness on the plasmonic enhancement of an n-i-p a-Si:H thin-film solar cell has been studied. The results show an increase in $J_{s c}$, efficiency and spectral response with the incorporation of the $\mathrm{Au}$ nanoparticles in both cells. It also shows that performance enhancement due to plasmonic nanoparticles is more effective for the $100 \mathrm{~nm}$ i-layer cell compared to $500 \mathrm{~nm}$ i-layer cell. For $100 \mathrm{~nm}$ i-layer cell, $J_{s c}$ increases from 5.91 to $6.5 \mathrm{~mA} / \mathrm{cm}^{2}(\sim 10 \%$ relative increase $)$ and efficiency increases from $3.38 \%$ to $3.97 \%(\sim 17.5 \%$ relative increase). And for $500 \mathrm{~nm}$ i-layer cell, $J_{s c}$ increases from 9.34 to $10.04 \mathrm{~mA} / \mathrm{cm}^{2}(\sim 7.5 \%$ relative increase) and efficiency increases from $4.27 \%$ to $4.99 \%$ ( $\sim 16.9 \%$ relative increase). EQE also shows similar trend of improvement after nanoparticle incorporation. $100 \mathrm{~nm}$ i-layer cell shows $13.33 \%$ enhancement of the peak after nanoparticle incorporation whereas $500 \mathrm{~nm}$ i-layer cell shows only $6.57 \%$ enhancement of the peak. Finally, the results highlight a promising and simple enhancement for future thin film solar cells using plasmonic Au nanoparticles.

\section{Acknowledgment}

We gratefully acknowledge financial support for this work provided by the Masdar Institute of Science and Technology.

\section{References}

Abdul Hadi, S., Hashemi, P., DiLello, N., Polyzoeva, E., Nayfeh, A., Hoyt, J.L., 2014. Thin-film $\mathrm{Si}_{1-x} \mathrm{Ge}_{x}$ HIT solar cells. Sol. Energy 103, 154-159. http://dx.doi.org/10.1016/j.solener.2014.01.039.

Abdul Hadi, S., Hashemi, P., Nayfeh, A., Hoyt, J., 2011. Thin film a-Si/cSi. In: ECS Transactions. The Electrochemical Society, pp. 3-14. doi: http://dx.doi.org/10.1149/1.3628603.

Akimov, Y.A., Koh, W.S., 2010. Resonant and nonresonant plasmonic nanoparticle enhancement for thin-film silicon solar cells. Nanotechnology 21, 235201. http://dx.doi.org/10.1088/0957-4484/21/ 23/235201.

Alnuaimi, A., Islam, K., Nayfeh, A., 2013. Reduction of interface traps at the amorphous-silicon/crystalline-silicon interface by hydrogen and nitrogen annealing. Sol. Energy 98, 236-240. http://dx.doi.org/ 10.1016/j.solener.2013.10.003.

Atwater, H.a., Polman, A., 2010. Plasmonics for improved photovoltaic devices. Nat. Mater. 9, 205-213. http://dx.doi.org/10.1038/nmat2866.

Bermel, P., Luo, C., Zeng, L., Kimerling, L.C., Joannopoulos, J.D., 2007. Improving thin-film crystalline silicon solar cell efficiencies with photonic crystals. Opt. Express 15, 16986. http://dx.doi.org/10.1364/ OE.15.016986.

Campbell, M., Sharp, D., Harrison, M., Denning, R., Turberfield, A., 2000. Fabrication of photonic crystals for the visible spectrum by holographic lithography. Nature 404, 53-56. http://dx.doi.org/ 10.1038/35003523.

Catchpole, K.R., Polman, A., 2008. Plasmonic solar cells. Opt. Express 16, 21793. http://dx.doi.org/10.1364/OE.16.021793.
Chowdhury, F.I., Alnuaimi, A., Islam, K., Nayfeh, A., 2014. Efficiency enhancement in thin-film c-Si HIT solar cells using luminescent 2.85 nm silicon nanoparticles. In: 2014 IEEE 40th Photovoltaic Specialist Conference (PVSC). IEEE, pp. 2209-2213. doi: http://dx.doi.org/10. 1109/PVSC.2014.6925364.

Bohren, Craig F., Huffman, D.R., 1983. Absorption and Scattering of Light by Small Particles. Wiley, <http://onlinelibrary.wiley.com/book/ 10.1002/9783527618156> (accessed 06.09.15).

Derkacs, D., Lim, S.H., Matheu, P., Mar, W., Yu, E.T., 2006. Improved performance of amorphous silicon solar cells via scattering from surface plasmon polaritons in nearby metallic nanoparticles. Appl. Phys. Lett. 89, 239-241. http://dx.doi.org/10.1063/1.2336629.

Ferry, V.E., Sweatlock, L.A., Pacifici, D., Atwater, H.A., 2008. Plasmonic nanostructure design for efficient light coupling into solar cells. Nano Lett. 8, 4391-4397. http://dx.doi.org/10.1021/n18022548.

Haase, C., Stiebig, H., 2007. Thin-film silicon solar cells with efficient periodic light trapping texture. Appl. Phys. Lett. 91, 061116. http:// dx.doi.org/10.1063/1.2768882.

Heine, C., Morf, R.H., 1995. Submicrometer gratings for solar energy applications. Appl. Opt. 34, 2476-2482. http://dx.doi.org/10.1364/ AO.34.002476.

http://imagej.nih.gov/ij/ (accessed 02.03.15).

http://nanocomposix.com/pages/gold-nanoparticles-optical-properties (accessed 06.20.15)

http://www.mvsystemsinc.com/research-and-development-services/ (accessed 06.10.14).

http://www.pveducation.org/pvcdrom/pn-junction/absorption-coefficient (accessed 05.21.15).

http://www.sigmaaldrich.com/materials-science/nanomaterials/gold-nano particles.html (accessed 01.18.14).

Islam, K., Alnuaimi, A., Battal, E., Okyay, A.K., Nayfeh, A., 2014. Effect of gold nanoparticles size on light scattering for thin film amorphoussilicon solar cells. Sol. Energy 103, 263-268. http://dx.doi.org/10.1016/ j.solener.2014.02.023.

Islam, K., Alnuaimi, A., Okyay, A.K., Nayfeh, A., 2013. Improved efficiency of thin film a-Si:H solar cells with Au nanoparticles. In: 2013 IEEE 39th Photovoltaic Specialists Conference (PVSC). IEEE, pp. 1873-1876. doi: http://dx.doi.org/10.1109/PVSC.2013.6744508.

Li, X., Hylton, N.P., Giannini, V., Ekins-Daukes, N.J., Maier, S.A., 2014. Design guidelines for efficient plasmonic solar cells exploiting the trade-off between scattering and metallic absorption, 11.

Maier, S.A., Atwater, H.A., 2005. Plasmonics: localization and guiding of electromagnetic energy in metal/dielectric structures. J. Appl. Phys. 98, 011101. http://dx.doi.org/10.1063/1.1951057.

Martins, R., Ferreira, I., Cabrita, A., Fortunato, E., 2000. Improvement of a-Si: $\mathrm{H}$ device stability and performances by proper design of the interfaces. J. Non-Cryst. Solids 266-269 (Part 2; Part B) 1094-1098. Part 2; Pa, 1094-1098.

Michel, J., Kimerling, L.C., 2007. Design of highly efficient light-trapping structures for thin-film crystalline silicon solar cells. IEEE Trans. Electron Devices 54, 1926-1933. http://dx.doi.org/10.1109/TED.2007.900976.

Israelowitz, Miriam, Amey, Jennifer, Tao Cong, R.S., et al., 2014. Spin coated plasmonic nanoparticle interfaces for photocurrent enhancement in thin film Si solar cells. J. Nanomater. 2014, 1-9. http:// dx.doi.org/10.1155/2014/639458.

Naik, G.V., Shalaev, V.M., Boltasseva, A., 2013. Alternative plasmonic materials: beyond gold and silver. Adv. Mater. 25, 3264-3294. http:// dx.doi.org/10.1002/adma.201205076.

Paris, A., Vaccari, A., Calà Lesina, A., Serra, E., Calliari, L., 2012. Plasmonic scattering by metal nanoparticles for solar cells. Plasmonics 7, 525-534. http://dx.doi.org/10.1007/s11468-012-9338-4.

Prevo, B.G., Velev, O.D., 2004. Controlled, rapid deposition of structured coatings from micro- and nanoparticle suspensions. Langmuir 20, 2099-2107. http://dx.doi.org/10.1021/la035295j.

Shukla, N., Ahner, J., Weller, D., 2004. Dip-coating of FePt nanoparticle films: surfactant effects. J. Magn. Magn. Mater. 272-276, E1349E1351. http://dx.doi.org/10.1016/j.jmmm.2003.12.208. 
Soller, B.J., Hall, D.G., 2002. Scattering enhancement from an array of interacting dipoles near a planar waveguide. J. Opt. Soc. Am. B 19, 2437. http://dx.doi.org/10.1364/JOSAB.19.002437.

Sönnichsen, C., Franzl, T., Wilk, T., von Plessen, G., Feldmann, J., 2002. Plasmon resonances in large noble-metal clusters. New J. Phys. 4. http://dx.doi.org/10.1088/1367-2630/4/1/393, 93-93.

Stuart, H.R., Hall, D.G., 1998. Island size effects in nanoparticleenhanced photodetectors. Appl. Phys. Lett. 73, 3815. http:// dx.doi.org/10.1063/1.122903.

Temple, T.L., Bagnall, D.M., 2012. Broadband scattering of the solar spectrum by spherical metal nanoparticles. Prog. Photovoltaics Res. Appl. http://dx.doi.org/10.1002/pip.1237, n/a-n/a.
Temple, T.L., Bagnall, D.M., 2011. Optical properties of gold and aluminium nanoparticles for silicon solar cell applications. J. Appl. Phys. 109, 084343. http://dx.doi.org/10.1063/1.3574657.

Temple, T.L., Mahanama, G.D.K., Reehal, H.S., Bagnall, D.M., 2009. Influence of localized surface plasmon excitation in silver nanoparticles on the performance of silicon solar cells. Sol. Energy Mater. Sol. Cells 93, 1978-1985. http://dx.doi.org/10.1016/j.solmat.2009.07.014.

Xia, D., Biswas, A., Li, D., Brueck, S.R.J., 2004. Directed self-assembly of silica nanoparticles into nanometer-scale patterned surfaces using spin-coating. Adv. Mater. 16, 1427-1432. http://dx.doi.org/10.1002/adma.200400095.

Zhou, D., Biswas, R., 2008. Photonic crystal enhanced light-trapping in thin film solar cells. J. Appl. Phys. 103, 093102. http://dx.doi.org/10.1063/1.2908212. 